\title{
The health benefits of blackcurrants
}

\author{
Ashwin Gopalan, ${ }^{a}$ Sharon C. Reuben, ${ }^{a}$ Shamima Ahmed, ${ }^{a}$ Altaf S. Darvesh, ${ }^{a}$ Judit Hohmann ${ }^{b}$ \\ and Anupam Bishayee*c
}

Received 10th March 2012, Accepted 13th April 2012

DOI: 10.1039/c2fo30058c

The blackcurrant (Ribes nigrum L., Grossulariceae), a small, perennial shrub native to central Europe and northern Asia, is cultivated throughout the world, including the United States. In addition to its anecdotal use in traditional herbal medicine, modern laboratories have demonstrated the potent antiinflammatory, antioxidant and antimicrobial effects of blackcurrant constituents on a myriad of disease states. The properties of the blackcurrants are conferred from its biochemical constituents, some of which include anthocyans (specifically delphinidin-3- $O$-glucoside, delphinidin-3- $O$-rutinoside, cyanidin-3- $O$-glucoside and cyanidin-3- $O$-rutinoside), flavonols, phenolic acids and polyunsaturated fatty acids. A plethora of studies have been published with regards to its various therapeutic applications. This article attempts to summarize these studies, providing a general overview of the research in this field. Several studies focus on the therapeutic potential of blackcurrants with regards to hypertension and other cardiovascular-associated illnesses, neoplastic, neurodegenerative and ocular diseases, nephrolithiasis, and diabetic neuropathy. Safety concerns and future directions are also mentioned, suggesting the critical examination of the exact mechanism of action, specific radicalscavenging capabilities of the blackcurrants and the crucial need for well-designed clinical trials to ensure the successful use of blackcurrants in a clinical setting.

${ }^{a}$ Cancer Therapeutics and Chemoprevention Group, Department of Pharmaceutical Sciences, College of Pharmacy, Northeast Ohio Medical University, 4209 State Route 44, Rootstown, OH 44272, USA

${ }^{b}$ Department of Pharmacognosy, University of Szeged, Eötvös u. 6, 6720 Szeged, Hungary

${ }^{c}$ Department of Pharmaceutical Sciences, School of Pharmacy, American University of Health Sciences, 1600 East Hill Street, Signal Hill, CA 90755, USA. E-mail: abishayee@auhs.edu; Fax: +562-988-1791; Tel: +562-988-2278 ext. 2038

\section{Introduction}

Berries represent the most widely consumed fruits in the human diet. Accumulating evidence suggests that the edible, small, softfleshed and colorful fruits may have an enormous potential towards several health benefits. ${ }^{1-5} \mathrm{~A}$ few examples of these powerful fruits are black and red raspberries, strawberries,

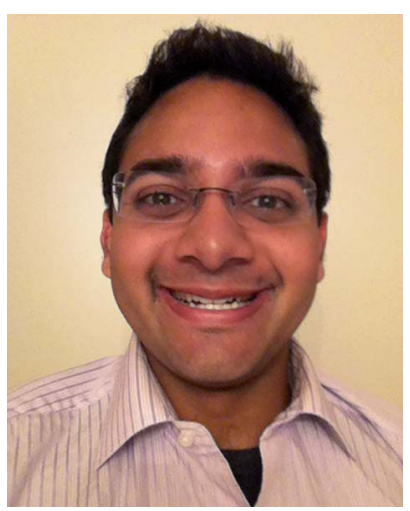

Ashwin Gopalan
In 2007, then-high school senior Ashwin Gopalan was accepted into the 6-year BS/MD program of Northeast Ohio Medical University, Rootstown, Ohio. Two years later in 2009, he graduated summa cum laude from Kent State University, Kent, Ohio, with a BS in Integrated Life Sciences. He is currently pursuing his MD at Northeast Ohio Medical University and is expected to graduate in May, 2013. Ashwin's research interests include nutrition, food science, and medical device development.

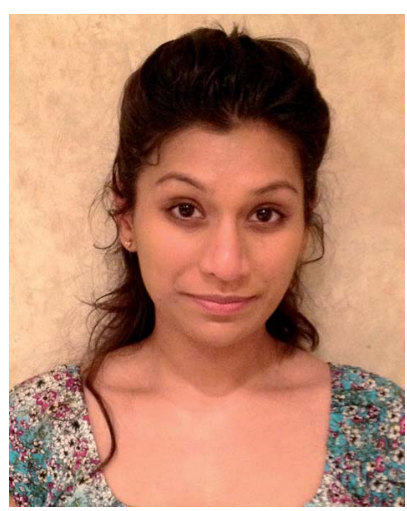

Sharon C. Reuben
Sharon C. Reuben completed her Bachelor of Science degree in Integrated Life Sciences in two years and graduated in 2009 from Kent State University in Kent, Ohio. She is currently a medical student at Northeast Ohio Medical University and anticipates the completion of her MD degree in May 2014. She has demonstrated an effective role by taking part in various local community health service opportunities as well as programs that encourage science education in high school students. Her research interests primarily involve cancer chemoprevention. 
blueberries, acai berries, noni berries, wolfberries, boysenberries and red as well as blackcurrants. Although berries contain macro- and micro-nutrients, such as fiber, minerals and vitamins, the large number of bioactive phytochemicals, including phenolic compounds, present in these fruits has been considered responsible for the various health-promoting and disease preventive effects. ${ }^{6-12}$

The blackcurrant originated from Northern Asia and Central and Eastern Europe and is widely cultivated in most countries of Europe as well as New Zealand. This small perennial shrub grows 1-2 meters tall with palmately lobed leaves with serrated margins (Fig. 1). The plant produces purple-black, sweet, aromatic, edible and seed-containing berries of up to $12 \mathrm{~mm}$ in diameter. The berry fruit has a glossy skin with a persistent apical calyx. An established shrub can produce up to five kilograms of blackcurrant berries in summer. The blackcurrant fruit was first domesticated between $400-500$ years ago, making it a relatively new addition to the agricultural arsenal. ${ }^{13}$

Blackcurrant fruits and leaves find use in both Asian and European traditional medicine for the treatment of a variety of ailments. ${ }^{14,15}$ Blackcurrants are also popularly used to prepare "cassis liqueur," a traditional alcoholic beverage in France.

In the early 1900s, the blackcurrant was banned from the United States, as it was perceived to be a vector for the fungus which causes white pine blister rust, which impacted heavily on the logging industry. The ban was later lifted in some states in 2003. The legality now varies by state. Currently, blackcurrants are grown in the several regions of the east and west coast.

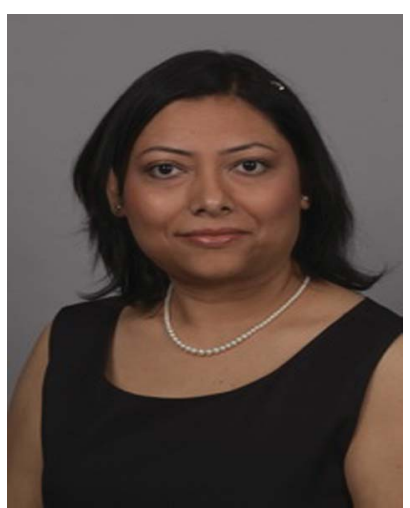

Shamima Ahmed
Shamima Ahmed will receive an MD in May 2012 from Northeast Ohio Medical University in Rootstown, Ohio. She completed her BA degree from Hunter College, City University of New York, New York. Her research experience and interests include alternative and complementary medicine, cancer chemoprevention by natural products, functional foods, and novel radiological diagnostic tools in neurological complications. She is very active in community leadership, advocacy and professional activities.

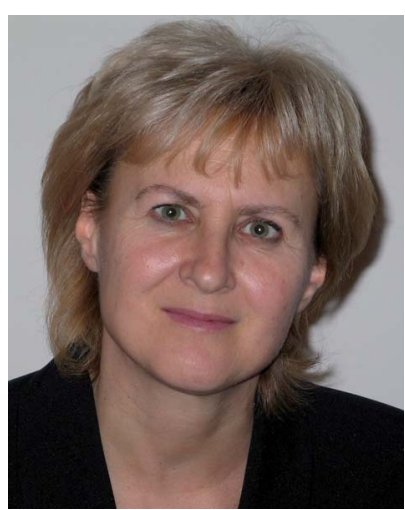

Judit Hohmann

Judit Hohmann is the head of the Department of Pharmacognosy at the Faculty of Pharmacy, University of Szeged, Szeged, Hungary. She obtained an MSc degree in Pharmacy at the University of Medical School in Szeged and received a PhD degree in 1995, and DSc degree in 2006 in Chemical Science. Her research program addresses the discovery of new biologically active secondary plant metabolites, including phenolic compounds, terpenoids and alkaloids. Her current research interests involve the activity-directed isolation, structure elucidation and structure-activity relationships of natural products from medical plants, such as the Euphorbiaceae, Asteraceae, Ranunculaceae, Lamiaceae and Polygonaceae family.

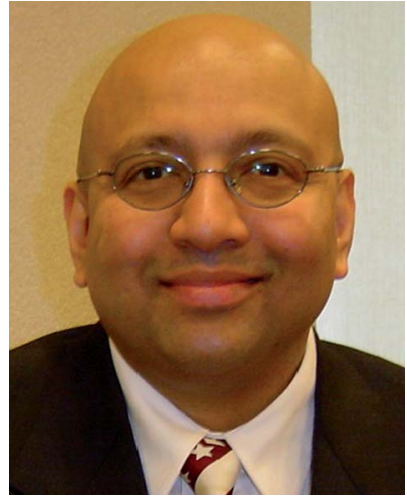

Anupam Bishayee
Anupam Bishayee is the Founding Chair and Associate Professor in the Department of Pharmaceutical Sciences in the School of Pharmacy at the American University of Health Sciences, Signal Hill, California. $\mathrm{Dr}$ Bishayee earned a PhD in Cancer Chemoprevention at Jadavpur University, Kolkata, India. $\mathrm{Dr}$ Bishayee's primary research experience and expertise, during the past two decades, has been the elucidation of cancer preventive and therapeutic effects of medicinal plants, natural products, and dietary agents using pre-clinical models of cancer. His laboratory is currently examining the mechanism-based chemopreventive and therapeutic potential of various phytoconstituents as well as synthetic agents in liver and breast cancer. 


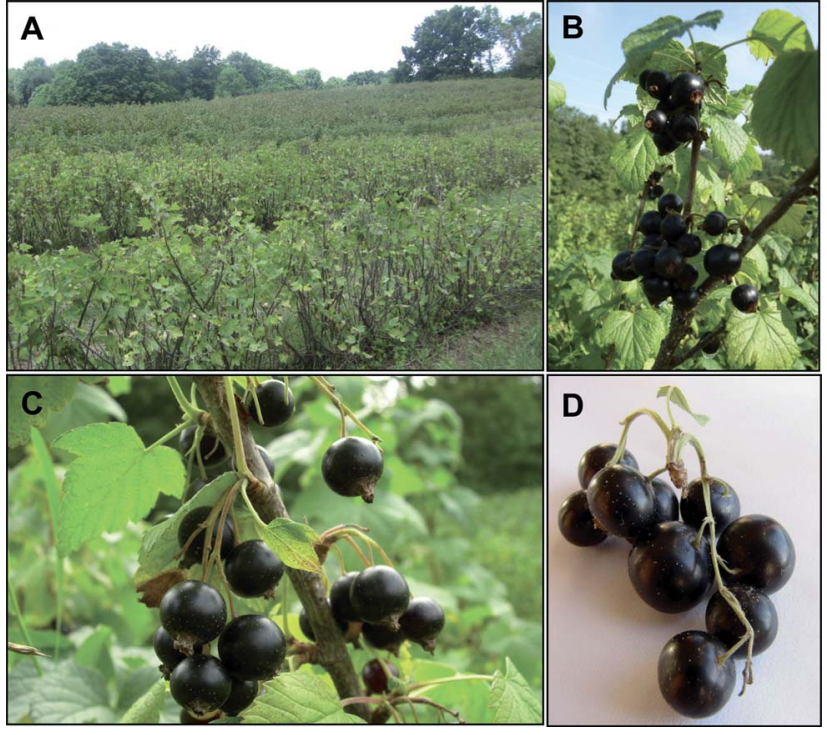

Fig. 1 Various photographs of blackcurrants (Ribes nigrum) showing a commercial blackcurrant plantation (A), the shrub with fruits (B and C), and isolated fruits (D).

A major hindrance in its production was the cold weather characteristic of its native lands. Frost damage led to an inconsistency in crop production, which lowered its commercial viability. The "Ben" series of cultivar was one particular solution offered by the Scottish Crop Research Institute. It is a hybrid that utilized germplasms from both high yielding cultivars and cultivars resistant to frost, making an ideal plant for commercialization. ${ }^{16}$

Apart from its colorful background, the blackcurrant has many therapeutic applications that have tremendous potential for further exploration. In this review, we highlight the potential therapeutic applications of blackcurrants. This article reviews the key phytochemical constituents present along with their principal mechanistic effects. The pre-clinical and clinical effects of blackcurrant products in various disease states is systematically tabulated and reviewed. Also discussed are the future directions needed to pursue blackcurrant's therapeutic success.

\section{Phytochemical constituents}

Biochemical profiling of blackcurrants has revealed a myriad of constituents: flavonoids, polyunsaturated fatty acids (PUFA), structural and nonstructural carbohydrates, non-volatile organic acids, tannins and stilbenoids. ${ }^{17-19}$

Blackcurrant flavonoids, a group of polyphenolic compounds with a diphenylpropane skeleton, include anthocyanins and flavonols. ${ }^{20}$ Blackcurrants are an important source of anthocyanins with concentrations up to four-fold greater than other common fruits. Studies in various genotypes of blackcurrants reveal a varied anthocyanin content of $80-280 \mathrm{mg}$ per $100 \mathrm{~g}$ of fruit with maximum levels observed up to $300 \mathrm{mg}$ per $100 \mathrm{~g}$ of fruit. ${ }^{21-24}$ The aglycones (anthocyanidins) are salt derivatives of the 2-phenylchromenylium (flavylium) cation. Its positive charge differentiates anthocyanidins from other flavonoids. Anthocyanins are sugar derivatives of anthocyanidins. Four major anthocyanins have been identified in the blackcurrant: delphinidin-3- $O$-glucoside, delphinidin-3-O-rutinoside, cyanidin-3-O-glucoside, and cyanidin-3-O-rutinoside (Fig. 2). ${ }^{25-27}$ Cyanidin possesses a hydrogen atom at the $5^{\prime}$ position, while delphinidin possesses a hydroxyl group at the $5^{\prime}$ position. ${ }^{25}$ The minor pigments of the berries are pelargonidin-3-O-rutinoside and pelargonidin-3-O-glucoside, cyanidin-3-O-sophoroside and cyanidin-3-O-arabinoside, delphinidin-3-O-sophoroside, peonidin-3-O-rutinoside and peonidin-3-O-glucoside, malvidin-3-Orutinoside and malvidin-3-O-glucoside, delphinidin-3-O-(6'coumaroylglucoside) and cyaniding-3-O-(6'-coumaroylglucoside) (Fig. 2), which were identified via a HPLC-DAD-MS technique after enrichment of the crude extract. ${ }^{28}$ Proanthocyanidins are oligomer or polymer chains of flavonoids, such as catechins (flavan-3-ols), and are also known as procyanidins, or condensed tannins. ${ }^{29}$

Flavonols are a class of compound which possess a 3hydroxyflavone backbone. The principal flavonols found in blackcurrants are quercetin, myricetin, kaempferol (Fig. 3) and their glycosides. ${ }^{16}$ Recognized to be present in blackcurrant using HPLC-ESI-MS, the main glycosides of myricetin, kaempferol and quercetin are rutinosides, glucosides and hexosidemalonates. ${ }^{26,30}$

Among PUFAs, $\gamma$-linolenic acid (GLA, Fig. 3 ) is an essential polyunsaturated fatty acid found in blackcurrants. GLA has been isolated from the blackcurrant seed oil. ${ }^{31,32}$ Studies suggest that the increased expression of the RnD6D gene (coding for a $\Delta^{6}$-desaturase, required for GLA synthesis) may explain this phenomenon. ${ }^{33}$ Studies show that, particularly in the "Ben More" and "Ben Connan" cultivars, there is a high GLA content in the seeds of the blackcurrant fruit, ranging from<smiles>Oc1cc(O)c2c(c1)OC(c1cc([Tl])c(O)c([Tl])c1)=C(Oc1cc3c(O)cc(O)cc3c(O)c1O)O2</smiles>

\begin{tabular}{|l|l|l|l|}
\hline Compound & $\mathrm{R}^{\mathbf{1}}$ & $\mathbf{R}^{\mathbf{2}}$ & $\mathrm{R}^{\mathbf{3}}$ \\
\hline Delphinidin-3-O-glucoside & $\mathrm{OH}$ & $\mathrm{OH}$ & $\mathrm{H}$ \\
\hline Delphinidin-3-O-rutinoside & $\mathrm{OH}$ & $\mathrm{OH}$ & rhamnosyl \\
\hline Delphinidin-3-O-(6"-coumaroylglucoside) & $\mathrm{OH}$ & $\mathrm{OH}$ & coumaroyl \\
\hline Delphinidin-3-O-sophoroside & $\mathrm{OH}$ & $\mathrm{OH}$ & glucosyl \\
\hline Cyanidin-3-O-glucoside & $\mathrm{OH}$ & $\mathrm{H}$ & $\mathrm{H}$ \\
\hline Cyanidin-3-O-rutinoside & $\mathrm{OH}$ & $\mathrm{H}$ & rhamnosyl \\
\hline Cyanidin-3-O-sophoroside & $\mathrm{OH}$ & $\mathrm{H}$ & glucosyl \\
\hline Cyanidin-3-O-(6"-coumaroylglucoside) & $\mathrm{OH}$ & $\mathrm{H}$ & coumaroyl \\
\hline Petunidin-3-O-glucoside & $\mathrm{OMe}$ & $\mathrm{OH}$ & $\mathrm{H}$ \\
\hline Petunidin-3-O-rutinoside & $\mathrm{OMe}$ & $\mathrm{OH}$ & rhamnosyl \\
\hline Pelargonidin-3-O-glucoside & $\mathrm{H}$ & $\mathrm{H}$ & $\mathrm{H}$ \\
\hline Pelargonidin-3-O-rutinoside & $\mathrm{H}$ & $\mathrm{H}$ & rhamnosyl \\
\hline Peonidin-3-O-glucoside & $\mathrm{OMe}$ & $\mathrm{H}$ & $\mathrm{H}$ \\
\hline Peonidin-3-O-rutinoside & $\mathrm{OMe}$ & $\mathrm{H}$ & rhamnosyl \\
\hline Malvidin-3-O-glucoside & $\mathrm{OMe}$ & $\mathrm{OMe}$ & $\mathrm{H}$ \\
\hline Malvidin-3-O-rutinoside & $\mathrm{OMe}$ & $\mathrm{OMe}$ & rhamnosyl \\
\hline
\end{tabular}

Fig. 2 Chemical structures of the major anthocyans present in blackcurrants. 
<smiles>Cc1cc(C)c2c(=O)cc(-c3ccc(O)c(O)c3)oc2c1</smiles>

Quercetin<smiles>O=c1c(O)c(-c2cc(O)c(O)c(O)c2)oc2cc(O)cc(O)c12</smiles>

Myricetin<smiles>O=c1c(O)c(-c2ccc(O)cc2)oc2cc(O)cc(O)c12</smiles><smiles>CCCCC/C=C\C/C=C\C/C=C\CCCCC(=O)O</smiles>

Kaempferol

Gamma Linoleic Acid<smiles>O=C1C2=CC(O)=C(O)C3OC(=O)C2c2c1cc(O)c(O)c2OC3=O</smiles>

Ellagic Acid

Gallic Acid<smiles>O=C(O)c1cc(O)c(O)c(O)c1</smiles>

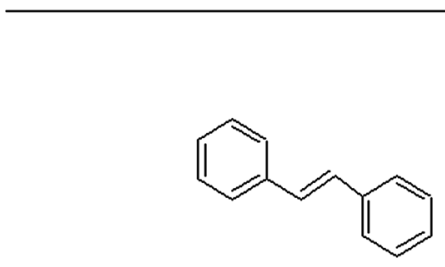

Stilbene<smiles>CC1=C(C)[C@H]([C@H](O)CO)OC1=O</smiles>

L-ascorbic Acid

Fig. 3 Chemical structures of the major phytoconstituents present in blackcurrants.

$18.1-22.7 \%$ of the seed by weight. Of the 29 genotypes of blackcurrant examined, the total fatty acid content of the blackcurrant seeds had a greater variance, which ranged from 7.6-19.3\%. Stearidonic acid $((6 Z, 9 Z, 12 Z, 15 Z)-6,9,12,15$-octadecatetraenoic acid), an $\omega-3$ fatty acid, has also been isolated from the blackcurrant seed oil. ${ }^{34}$ Production of stearidonic acid requires the precursor $\alpha$-linolenic acid along with a $\Delta^{6}$-desaturase enzyme, similar to GLA.

Carbohydrate structures pervade the architectural elements of blackcurrants. Examples of such are high molecular weight galactans, which possess side chains comprised of galacturonic acid, galactose, and arabinose residues. Arabinogalactan proteins have galactose and arabinose residues and additionally include xylose carbohydrate residues as well. ${ }^{35,36}$

L-ascorbic acid (Fig. 3), also known as vitamin C, is an essential non-volatile organic acid and a potent antioxidant and free radical scavenger. Several studies have evaluated the ascorbic acid content in blackcurrants, which was found to vary between 70-280 mg per $100 \mathrm{~g}$ of fresh fruit. Thus blackcurrants are a major source of this vital vitamin, which in turn provides blackcurrants with its powerful antioxidant effects. ${ }^{2,23,34,37}$
Ellagitannins, a type of hydrolyzable tannins, are a diverse class of polyphenols composed of ellagic acids (Fig. 3) linked to hydroxyl groups of a polyol carbohydrate compound, such as glucose. Gallotannins are another class of hydrolyzable tannins. Similar to ellagitannins, gallotannin polymers are formed when gallic acid (Fig. 3) links to the hydroxyl groups of polyol carbohydrates. Both of these compounds have been isolated from blackcurrant juices and contribute significantly towards some of its healing properties. ${ }^{38}$

Different types of hydroxylated phenolic acids are also present in blackcurrant fruit both in non-glycosylated and glycosylated forms. The most important compounds are gallic acid, $p$ hydroxy-benzoic acid and hydroxycinnamic acid derivatives. ${ }^{26,39}$

Stilbenoids (Fig. 3) have been isolated from blackcurrants. ${ }^{40}$ These compounds have also been identified in many other fruit products as well as red wine, due to the grapes, and have been proven to have a positive impact on human health.

Blackcurrants also contain a rich mineral composition which may contribute to their health benefits. Analysis of blackcurrant constituents reveals that the fruits possess high levels of minerals, especially potassium, calcium, magnesium as well as iron. ${ }^{23,41}$ 


\section{Biological effects of blackcurrants}

\section{Anti-inflammatory and immuno-modulatory responses}

The heart of the inflammatory response is mediated by a cascade of eicosanoids, signalling molecules made from the oxidation of twenty carbon essential fatty acids (EFA). There are multiple variants of each type of eicosanoid, whose characteristics are dependent on the precursor EFA used to synthesize it. There are three main EFA precursors that have been identified in synthesis-eicosapentanoic acid (EPA), dihomo- $\gamma$-linolenic acid (DGLA), and arachidonic acid (AA). Eicosanoids synthesized by AA are the most effective in eliciting an immune response. Eicosanoids rising from EPA or DGLA are less effective towards evoking an immune response and compete with the more "efficient" eicosanoids synthesized by AA, hence they are seen to have an anti-inflammatory response. Blackcurrant seed oil is rich in GLA (a precursor to DGLA), alpha linolenic acid, and stearidonic acid, which are precursors to EPA. ${ }^{34,42,43}$ Barre $^{44}$ has reviewed in detail the anti-inflammatory properties and their resulting health effects of blackcurrant oil.

In addition to the eicosanoids, contributions to the progression of the immune response are executed by many other signaling molecules: tumor necrosis factor- $\alpha$ (TNF- $\alpha$ ), interleukins (IL) 1-6, nitric oxide (NO) and nuclear factor- $\kappa \mathrm{B}(\mathrm{NF}-\kappa \mathrm{B})$. Studies involving an in vitro administration of blackcurrant extract revealed a suppressive effect against TNF- $\alpha$ in the presence of lipopolysaccharide (LPS), an immunogenic bacterial product known to provoke a systemic inflammatory response syndrome and to cause septic shock. Molecules downstream of this pathway, specifically NF- $\kappa$ B and IL-6 were also downregulated, which further indicated acute phase cytokine inhibition. $^{45}$ There is, however, some contradictory data. An increase in NF- $\mathrm{B}$ production was demonstrated in the presence of LPS in the liver tissue of a transgenic mice model. This could suggest that blackcurrants may modulate inflammation differently in various tissues. ${ }^{46} \mathrm{~A}$ specific mechanism for this phenomenon has yet to be proposed and additional studies are required to delineate the particulars.

Along the same lines, with regard to acute phase cytokine inhibition, another study was conducted in a rat model involving the administration of carrageenan (CGN), a family of linear sulfated polysaccharides with known immunogenic effect. ${ }^{47}$ CGN induces inflammation through activation of the kininkallikrein system, which in turn results in the accumulation of leukocytes and the production of acute phase cytokines and eicosanoids. Proanthocyanidin (PAC), isolated from blackcurrant leaves, was administered to mitigate the effects of CGN. Paw edema, pleural exudates and leukocyte migration were notably reduced while the concentrations of TNF- $\alpha$, interleukins and NO were also decreased. ${ }^{48} \mathrm{NO}$, an oxidative radical, serves many roles in the immune response by causing edema via vasodilation of local blood vessels, directly inducing oxidative damage against bacterial structures and inhibiting leukocyte migration. ${ }^{49}$ PAC has an ability to scavenge free radicals and thus PAC can absorb and negate the effect of NO. ${ }^{50}$ However, given that both $\mathrm{NO}$ concentration and leukocyte migration were simultaneously reduced, it suggests that PAC may have a direct activity on the transmigration of leukocytes, although the direct mechanism of how this occurs has yet to be explored. ${ }^{48}$ The antiinflammatory properties of blackcurrants traverses across multiple pathways and have effects on many targets. Some of these pathways are well-known, while others require additional exploration.

\section{Antioxidant properties}

Oxidative stress is characterized by the introduction of reducing agents, such as oxygen free radicals, into a cellular environment, wherein the heightened chemical reactivity of the agent disrupts the structure and thus the function of cellular machinery. An antioxidant would hence possess the ability to mitigate the chemical reactivity of the agent by neutralizing it. States of increased oxidative stress can be seen in disease, smoking activity and physical exercise in unconditioned individuals. ${ }^{51}$

Multiple accounts show empirical support regarding the antioxidant ability of blackcurrants. ${ }^{38,52}$ Data from additional studies demonstrates the neutralization of hydrogen peroxide $\left(\mathrm{H}_{2} \mathrm{O}_{2}\right)$ and $\mathrm{NO}$, as well as impeding the propagation of lipid and protein peroxidation. ${ }^{53-55}$ Antioxidant enzymes, such as glutathione $(\mathrm{GSH})$ peroxidase and superoxide dismutase, were also shown to increase significantly by the blackcurrant components through an unknown mechanism. ${ }^{56}$

The specific antioxidant capacities of the blackcurrant fruit as a whole are mostly bequeathed to its phenolic and anthocyan content. ${ }^{24,57}$ This content can vary widely depending on the cultivar, season it was grown in, state of ripening and the particular part of the plant used. ${ }^{16}$ Although the phenolic content is considered to contribute a more potent antioxidant activity than natural vitamins, high levels of vitamin $\mathrm{C}$ confers the additional inherent antioxidant properties to blackcurrants. ${ }^{20,58}$

Following oral consumption, the antioxidant activity of anthocyanins in blackcurrants is affected by the $\mathrm{pH}$ of its environment, potentially due to a shift in its prototropic equilibrium. ${ }^{59}$ Free radical scavenging activity was noted to attain maximum levels at a $\mathrm{pH}$ between 6.0 and 7.0, slightly more acidic than human serum. ${ }^{60,61}$ This suggests that the anthocyanin antioxidant activity potentially varies depending on its location in the human body.

Studies involving human subjects drinking blackcurrant juice revealed an increase in serum sulfahydryl group levels within two hours of consumption. Additional in vitro studies quantified a $94 \%$ inhibition of copper ion-induced low density lipoprotein (LDL) oxidation. ${ }^{62}$

\section{Antimicrobial mechanisms}

Acidic, high molecular weight galactans found in blackcurrant seed extracts were shown to have anti-adhesive effects against Helicobacter pylori in sections of the human gastric mucosa, thus carrying antidotal prospects for virtually all duodenal ulcers. ${ }^{35}$ Although unknown, it has been postulated that the mechanism of action may involve blocking the interactions between the mucosal epithelial cells and the surface receptors of the organism. With regards to the microbial effects on the composition of the particular constituents of the blackcurrants, microbial enzymes were found to deconjugate glycosylated compounds, such as anthocyanins. ${ }^{63}$ Specifically, gram-positive organisms were 
found to be more proficient at this glycosylation reaction when compared to gram-negative organisms. Anthocyanins have been demonstrated to possess antimicrobial capabilities against a variety of bacteria, but gram-positive bacteria tend to be more susceptible than gram-negative bacteria. Mechanisms underlying its activity involve both intracellular as well as membrane interactions. ${ }^{64}$ In vitro studies show that $H$. pylori, salmonella species and Bacillus cereus are sensitive to phenolic-induced destruction of their outer cell wall, whereas other organisms, such as Campylobacter jejuni and Candida albicans species, are notably susceptible to degradation by ellagitannins. ${ }^{65}$ The mechanism of destruction is not well elucidated.

Anthocyanins and blackcurrant extract have been shown to inhibit peridontopathogenic proteinases, specifically those of Porphyromonas gingivalis, Tannerella forsythia and Treponema denticola, which allow these organisms to extract usable nutrients from their environments. ${ }^{66}$ They have also been shown to inhibit matrix metalloproteinases 1 and 9, which break down collagen fibrils into smaller peptides and amino acids, which can serve as a nutrient source for periodontopathogens and facilitate bacterial growth in the oral cavity.

The anti-herpetic effects of blackcurrant fruit extract were tested in vitro. Blackcurrants were shown to inhibit the herpes simplex virus type 1 attachment onto the cell membrane, as well as the plaque formation of herpes simplex virus types 1 and 2 and the Varicella-Zoster virus via the inhibition of protein synthesis in the early stages of infection. ${ }^{15}$

Anthocyanins extracted from blackcurrants were shown to have potent activity against influenza viruses A and B. Extracts were shown to directly inactivate both viruses, as well as prevent spread. ${ }^{67}$ Specifically, delphinidin was shown to inhibit virus adsorption as well as release. ${ }^{68}$

\section{In vitro pharmacological effects of blackcurrants}

\section{Cardiovascular system}

Testing with blackcurrant juice in vitro demonstrated an improvement in the attenuation of serum cholesterol by macrophages of the $\mathrm{J} 774 \mathrm{~A}$ cell line. This resulted in an increased expression of paraoxanase 1, a major anti-atherosclerotic component of HDL (Table 1). ${ }^{62}$ It was also demonstrated that blackcurrants increase the activation of endothelial NO synthase in human umbilical vein endothelial cells. ${ }^{69} \mathrm{NO}$ activation results in the dilation of blood vessels and is a major mechanism of action for many cardiovascular therapies.

\section{Nervous system}

Blackcurrants have been noted to have interesting results in experimentation in vitro concerning potential neuronal applications. In order for proper neurotransmission to occur, action potentials must travel along the lengths of neurons and are thus dependent on sodium, calcium, and potassium ion channels. Blackcurrant extract was shown to increase the recovery of calcium flux in type 1 muscarinic receptors in COS-7 cells following toxic stresses mimicking Alzheimer's disease and neuronal aging. ${ }^{70}$

\section{Pulmonary system}

Purified blackcurrant proanthocyanidins were able to amplify interferon-gamma-induced suppression of IL-4 induced CCL26 secretion in a A549 alveolar epithelial cell line. CCL26 is a major factor in eosinophilic activation seen in atopic asthma and hence, blackcurrants were shown to have potential towards relieving eosinophilic-driven pulmonary inflammation. ${ }^{71}$

\section{Tumors}

Several studies have investigated the anticancer potential of blackcurrants using several tumor cells of human origin. The whole fruit extract has been shown to inhibit the proliferation of HT29 colon cancer and MCF-7 breast cancer cells. ${ }^{72}$ A subsequent study confirmed the anti-proliferative effect of blackcurrant extract against HT29 colon cancer cells and revealed the suppression of the $\mathrm{p} 21^{\mathrm{WAF} 1}$ pathway as the underlying mechanism. ${ }^{73}$ McDougall and colleagues ${ }^{74}$ reported a similar growth inhibitory action of an extract prepared using the whole fruit against HeLa cervical cancer cells. Boivin and co-investigators ${ }^{75}$ compared the anticancer potential of various juices obtained from 13 edible berry fruits utilizing a panel of stomach, colon, breast and prostate tumor cells. The results indicated that blackcurrant juice possessed the second best anti-proliferative effect against various cancer cells. Mechanistic data revealed that the blackcurrant juice-mediated antitumor effect in prostate cancer cells involves cell-cycle arrest, inhibition of TNF-induced activation of cyclooxygenase (COX-2) expression and suppression of TNFinduced $\mathrm{NF}-\kappa \mathrm{B}$-dependent reporter gene transcription. A polysaccharide-rich substance isolated from blackcurrant juice, known as cassis polysaccharide (CAPS), has been shown to exhibit cytotoxicity against Ehrlich ascites tumor cells. ${ }^{76}$ Recently, blackcurrant press residue extracts, obtained following extraction at various temperatures, were tested for their ability to inhibit the proliferation of several human colon cancer cell lines, namely Caco-2, HT-29 and HCT 116. All the extracts exhibited dosedependent inhibition of the cell proliferation against all three cell lines. A parallel induction of apoptosis has been observed when HT-29 cells were exposed to the extract obtained at $90{ }^{\circ} \mathrm{C} .{ }^{77}$

Our laboratory has initiated a comprehensive research program to investigate the antitumor and chemopreventive potential of blackcurrants against hepatocellular carcinoma (HCC). Recently, we have isolated an anthocyanin-rich fraction, containing cyanidin-3-O-rutinoside as the predominant anthocyanin, from blackcurrant skin which is normally considered as a low-value byproduct of blackcurrant juice production. Utilizing an in vitro tumor model employing HepG2 human liver cancer cells, we have further demonstrated that this anthocyaninrich fraction possesses a potent cytotoxic effect against $\mathrm{HCC}^{78}$

\section{In vivo pharmacological effects of blackcurrants}

\section{Cardiovascular system}

The ingestion of blackcurrants results in several beneficial health consequences, demonstrated in vivo, and one is evident in the cardiovascular system (Table 2). Multiple studies have been conducted in animal models, demonstrating its efficacy in mitigating various cardiovascular ailments. A study examining rats with 
Table 1 In vitro pharmacological effects of blackcurrants

\begin{tabular}{|c|c|c|c|}
\hline Blackcurrant fraction & Cell line & Pharmacological effect & Reference \\
\hline \multicolumn{4}{|c|}{ CARDIOVASCULAR SYSTEM } \\
\hline Juice & J774A.1 macrophage cell line & $\begin{array}{l}\text { Increased paraoxanase } 1 \text { expression, } \\
\text { improving macrophage cholesterol } \\
\text { attenuation }\end{array}$ & Rosenblat et al., $2010^{62}$ \\
\hline Extract & $\begin{array}{l}\text { Human umbilical vein endothelial } \\
\text { cells }\end{array}$ & $\begin{array}{l}\text { Increased activation of endothelial } \\
\text { NO synthase and dilation of blood } \\
\text { vessels }\end{array}$ & Edirisinghe et al., $2011^{69}$ \\
\hline \multicolumn{4}{|l|}{ NERVOUS SYSTEM } \\
\hline Extract & M1 transfected COS-7 cells & $\begin{array}{l}\text { Increased recovery of calcium flux in } \\
\text { type-1 muscarinic R's }\end{array}$ & Joseph et al., $2004^{70}$ \\
\hline \multicolumn{4}{|l|}{ PULMONARY SYSTEM } \\
\hline Extract (proanthocyanidin) & A549 alveolar epithelial cell line & $\begin{array}{l}\text { Induced CCL26 secretion and amplified } \\
\text { interferon-gamma }\end{array}$ & Hurst et al., $2010^{71}$ \\
\hline \multicolumn{4}{|c|}{ (1) } \\
\hline Whole fruit extract & $\begin{array}{l}\text { HT29 colon cancer; MCF-7 breast } \\
\text { cancer }\end{array}$ & $\begin{array}{l}\text { Decreased the proliferation of cancer } \\
\text { cells }\end{array}$ & Olsson et al., $2004^{72}$ \\
\hline Whole fruit extract & HT29 colon cancer & Inhibited cancer cell growth & Wu et al., $2007^{73}$ \\
\hline Whole fruit extract & HeLa cervical cancer & Reduced cell viability & McDougall et al., $2008^{74}$ \\
\hline Juice & $\begin{array}{l}\text { Caco- } 2 \text { colorectal adenocarcinoma; } \\
\text { MCF- } 7 \text { and MDA-MB- } 231 \text { breast } \\
\text { cancer; AGS stomach adenocarcinoma; } \\
\text { PC- } 3 \text { prostate cancer }\end{array}$ & Suppressed cancer cell proliferation & Boivin et al., $2007^{75}$ \\
\hline CAPS & Ehrlich ascites tumor & Exhibited cytotoxicity & Takata et al., $2005^{76}$ \\
\hline Press residue extracts & $\begin{array}{l}\text { Caco-2, HCT } 116 \text { and HT-29 colon } \\
\text { cancer }\end{array}$ & Inhibited cell proliferation & Holtung et al., $2011^{77}$ \\
\hline Skin extract & HepG2 liver cancer & Displayed antiproliferative effect & Bishayee et al., $2010^{78}$ \\
\hline
\end{tabular}

spontaneous hypertension were administered GLA from the oils of blackcurrants, and other agents containing oils enriched in GLA, for 7 weeks to demonstrate a notable decline in blood pressure levels. ${ }^{79}$ Interestingly, this study also tested the effects of vasoconstrictive hormones, such as norepinephrine and angiontensin II as well as a hypotensive-causing, calcium channel-blocking agent verapamil, against the results of GLA administration. The results found that the anti-hypertensive effects of GLA were not changed by either verapamil or the pressor hormones.

Blackcurrant oil, in conjunction with fish and olive oil, was shown to reduce serum levels of thromboxane B2, an inactive metabolite of thromboxane A2, a pro-thrombotic factor released by activated platelets. ${ }^{80}$ By decreasing thromboxane A2, there is a reduction in the risk of thrombus-formation, which leads to the development of cerebrovascular and cardiovascular incidents.

Specific studies involving cyanidin-3-O-glucoside suggested that anthocyanins had little effect on liver and plasma cholesterol levels and decreased the relative amount of hepatic saturated fatty acids. It was also shown to increase plasma tocopherol levels, suggesting a possible synergistic effect with vitamin $E$ to maximize antioxidant activity. ${ }^{81}$

Blackcurrant concentrate has been shown to induce vasorelaxation through endothelial histamine $\mathrm{H} 1$ receptors, indirectly increasing NO levels. ${ }^{82}$

In vivo analyses of blackcurrant seed oil on liver lipids and lipoprotein profiles demonstrated no accumulation of n-3 PUFAs in the liver. ${ }^{83}$ In addition, there was a significant decrease in plasma GSH. However, hepatic GSH levels were unaffected, as was the $t$-butyl hydroperoxide-induced lipoperoxidation. ${ }^{84}$ This result indicated that although blackcurrant seed oil does possess an antioxidant activity via other downstream effects, it does not mediate anti-oxidant effects through the GSH reduction system.
Increased vaso-relaxation results in an increased blood flow to organs such as the heart or brain, thus preventing the occurrence of a myocardial infarction or stroke. With respect to plasma lipoprotein content, anthocyanin-rich beverages were found to increase plasma LDL and cholesterol, while significantly lowering very low density lipoprotein (VLDL). ${ }^{56} \mathrm{~A}$ disparate result was observed in a study that exhibited the inhibitory effects of blackcurrant anthocyanin delphinidin-3-Orutinoside on endogenous vasodilators NO and cyclic GMP on bovine ciliary smooth muscle cells. ${ }^{85}$ In this study, delphinidin3-O-rutinoside levels were in fact attenuated according to the concentration of various substances that caused anthocyanin to act as either a nitric oxide synthase inhibitor, NO scavenger, or a guanylyl cylcase inhibitor. Additionally, concentrated blackcurrant delphinidin was shown to decrease peripheral vascular resistance in a rat hind-limb perfusion model. ${ }^{86}$ The mechanism of action with regards to delphinidin appeared to involve endothelial $\mathrm{NO}$ and $\mathrm{H}_{2} \mathrm{O}_{2}$.

\section{Nervous system}

Studies involving rat models validate that the modulatory effect of GLA (found in blackcurrants and other natural sources of fatty acids) on thromboxane A2 aids in diabetes-associated reduced sensory and motor nerve conduction velocity. ${ }^{87}$

\section{Ocular system}

The health benefits associated with blackcurrants can be extended to ocular health. Ocular bioavailability of blackcurrant anthocyanins administered in their intact forms has been demonstrated in animal models. ${ }^{88}$ In artificially induced myopia 
Table 2 In vivo pharmacological effects of blackcurrants

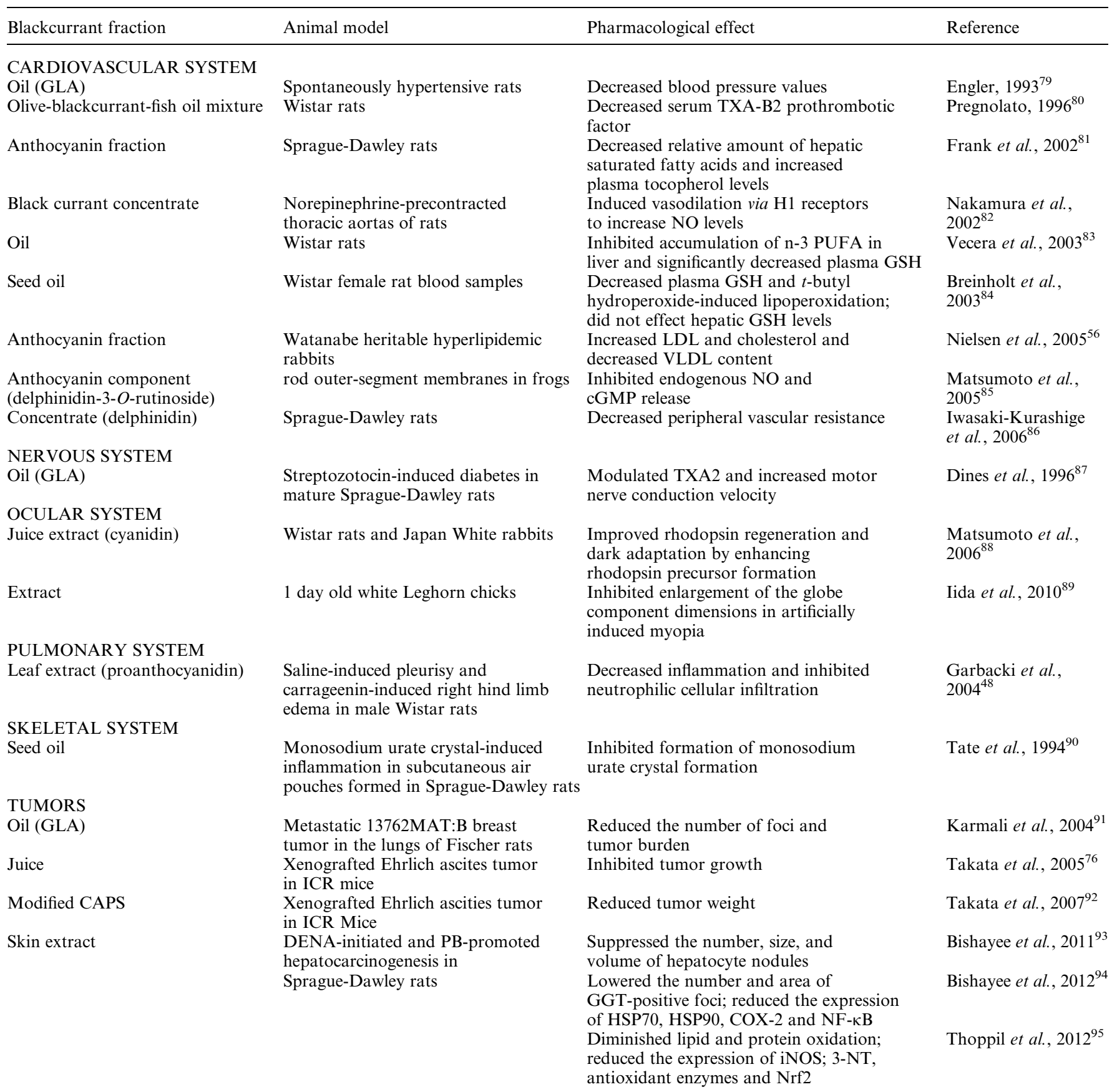

Abbreviations: cGMP $=$ cyclic guanosine monophosphate; GGT $=\gamma$-glutamyl transferase; GLA $=\gamma$-linolenic acid; GSH $=$ glutathione; LDL $=$ low density lipoprotein; $\mathrm{NO}=$ nitric oxide; PUFA = polyunsaturated fatty acid; TXA = thromboxane; VLDL = very low density lipoprotein.

through negative lenses in the chick animal model, blackcurrant extract was demonstrated to inhibit the enlargement of globe component dimensions, which would normally occur as an adjustment to the myopia. ${ }^{89}$

\section{Pulmonary system}

Proanthocyanidin content from blackcurrants is shown to improve conditions of the lung, such as pleurisy or chest pain, associated with the inflammation of the membranous lining and high exudative edema of the lungs in times of infection. This results from the anti-inflammatory properties of this biochemical constituent, which inhibits neutrophilic cellular infiltration, thereby inhibiting lung injury caused by the endogenous inflammatory process. ${ }^{48}$

\section{Skeletal system}

Blackcurrant seed oil was demonstrated to impede the formation of monosodium urate crystals during acute inflammation in vivo. ${ }^{90}$ 
Additionally, it was noted that both the cellular and fluid phases of inflammation, predominantly composed of polymorphonuclear leukocytes and exudate accumulation respectively, were significantly suppressed. By inhibiting the formation of monosodium urate crystals, it should be noted that the primary factor that precipitates the disease state of gout is thus inhibited.

\section{Tumors}

There are only three in vivo studies which document the antitumor effects of blackcurrant products in transplanted tumor models. Blackcurrant seed oil containing GLA was administered through the diet and suppressed the metastatic breast tumor in the lungs of rats. ${ }^{91}$ In another study, oral feeding of blackcurrant juice to Ehrlich carcinoma-bearing mice significantly abrogated solid tumor growth. ${ }^{76}$ The same research group also showed that CAPS contains an immunostimulatory activity and enzymatically digested CAPS afforded superior antitumor effects to that of native CAPS against a Ehrlich carcinoma model in mice. ${ }^{76,92}$

Our laboratory has evaluated the chemopreventive effect of phytoconstituents, derived from blackcurrant skin, against diethylnitrosamine (DENA)-induced hepatocellular carcinogenesis in rats. Dietary administration of the blackcurrant fraction exhibited a striking inhibition of incidence, multiplicity, size and volume of hepatocyte nodules, precursors of HCC, through suppression of abnormal cellular proliferation and induction of apoptosis. ${ }^{93}$ Our subsequent mechanistic study demonstrated that blackcurrant phytoconstituents suppressed the DENAinduced inflammatory cascade via interference with NF- $\mathrm{B}$ signaling. ${ }^{94}$ Based on our recent investigation, blackcurrant bioactive phytochemicals diminished DENA-inflicted oxidative insult through nuclear factor E2-related factor 2 (Nrf2)-mediated induction of antioxidants and phase 2 xenobiotic-metabolizing enzymes during rat hepatocarcinogenesis. ${ }^{95}$

\section{Clinical effects of blackcurrants in clinical studies}

\section{Cardiovascular system}

Several clinical studies have been completed regarding the effect of blackcurrants on the cardiovascular system (Table 3). It has been shown that blackcurrant seed oil acts as a platelet inhibitor due to its polyunsaturated fatty acid constituents, such as GLA, and potentiates an anti-coagulant effect by inhibiting fibrin formation. ${ }^{96}$

A clinical study of blackcurrant anthocyanins involving 20 healthy male volunteers showed an improved blood flow to the shoulder muscles during typing work as well as at rest, suggesting that it may improve shoulder stiffness and reduce muscle fatigue. ${ }^{97}$

Certain European diets provide a suboptimal level of eicosapentanoic and docosahexanoic acids, which are derived mainly from fish oil. A study using blackcurrant oil as a substitute revealed a further decrease in LDL cholesterol than that provided by fish oil, suggesting that blackcurrants may be a viable substitute. ${ }^{98}$ In a study involving peripheral artery disease, $500 \mathrm{ml}$ of blackcurrant juice was shown to reduce the serum inflammatory markers, such as C-reactive protein. Nevertheless, it was not shown to reduce the endothelial activation markers. ${ }^{99}$
Serum $\alpha$ - and $\gamma$-tocopherol concentrations were found to increase following blackcurrant seed administration. Blackcurrant seeds contain high levels of PUFAs as well as polyphenolic and tocopherol content, which help inhibit the oxidative damage to DNA, lipids and proteins seen in coronary heart disease, particularly concerning the generation of atherosclerotic plaques. ${ }^{51}$ Additional studies have demonstrated that administration of a blackcurrant soft oil capsule increases serum HDL-C protein while lowering triglyceride levels and total cholesterol in hyperlipidemic patients with a low body mass index, thus increasing a favorable lipid profile. ${ }^{100}$

Consumption of blackcurrant juice by healthy human subjects was shown to have no significant effect on total plasma nitrate, nitrite, intracellular adhesion molecules (ICAM) or vascular cell adhesion molecules (VCAM). In addition, there were no significant changes noted in the vascular reactivity when measured by laser doppler imaging. ${ }^{101}$

In a study where a purified anthocyanin extract was given to hypercholesterolemic individuals, flow-mediated dilation of the brachial artery was found to increase. This was postulated to be due to an increase in the NO-cGMP activation, which subsequently increased blood vessel diameter. In addition, improvements in the serum lipid profile and decreases in inflammatory markers were noted. ${ }^{102}$

\section{Nervous system}

The antioxidant properties of several of the chemicals found in blackcurrants have proven to have potential neuro-protective effects. Blackcurrant seed oil was demonstrated to improve serum fatty acid composition in patients afflicted by a stroke. ${ }^{103}$ Improving the serum fatty acid composition mitigates the poor lipid profile, which often causes or is associated with conditions such as stroke.

\section{Ocular system}

Multiple studies have established that cyanidin has been shown to improve rhodopsin regeneration and dark adaptations. This has the effect of improving visual discernment by the eye. A postulated mechanism for why this occurs revolves around the idea that anthocyanidins can enhance the formation of rhodopsin precursors. In addition, anthocyanins cause vasorelaxation, which can increase blood flow to the eye and reduce fatigue to improve eye function..$^{104,105}$

Blackcurrants have also shown efficacy in other ocular conditions such as Japanese Cedar Pollinosis. In this disease, CAPS was revealed to relieve naso-ocular symptoms. ${ }^{106}$

\section{Skeletal system}

Blackcurrant seed oil has been shown to reduce morning stiffness in rheumatoid arthritis in studies, which suggests a drop in IL-13, IL-1, TNF- $\alpha$ and other mediators of the inflammatory response. It did not, however, have any effect on grip or pain-score. ${ }^{31}$ Prodelphinidins in blackcurrant extract have shown promising results against the degenerative processes of osteoarthritis. It is suggested that its mechanism of action is related to its anti-inflammatory properties. ${ }^{107}$ Reduced pain intensity and improved disability are demonstrated after the administration of GLA. ${ }^{108}$ 
Table 3 Clinical effects of blackcurrants

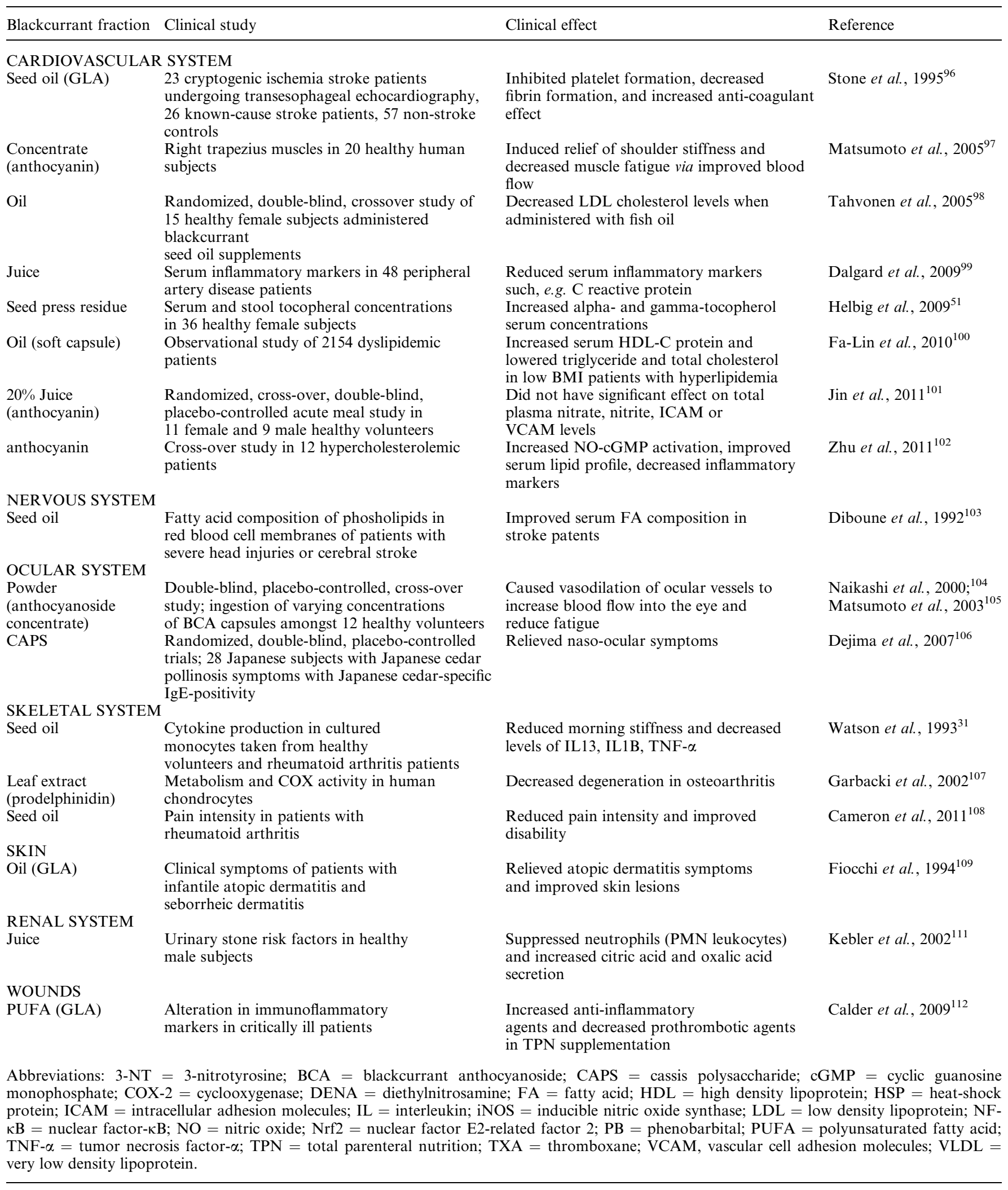

\section{Skin}

A study was conducted on children suffering from atopic dermatitis to demonstrate that a daily administration of $3 \mathrm{~g}$ of
GLA, one of the crucial biochemical constituents of blackcurrants, for the duration of approximately one month resulted in a significant respite from the condition while high levels of GLA content was present in the serum. This study also observed 


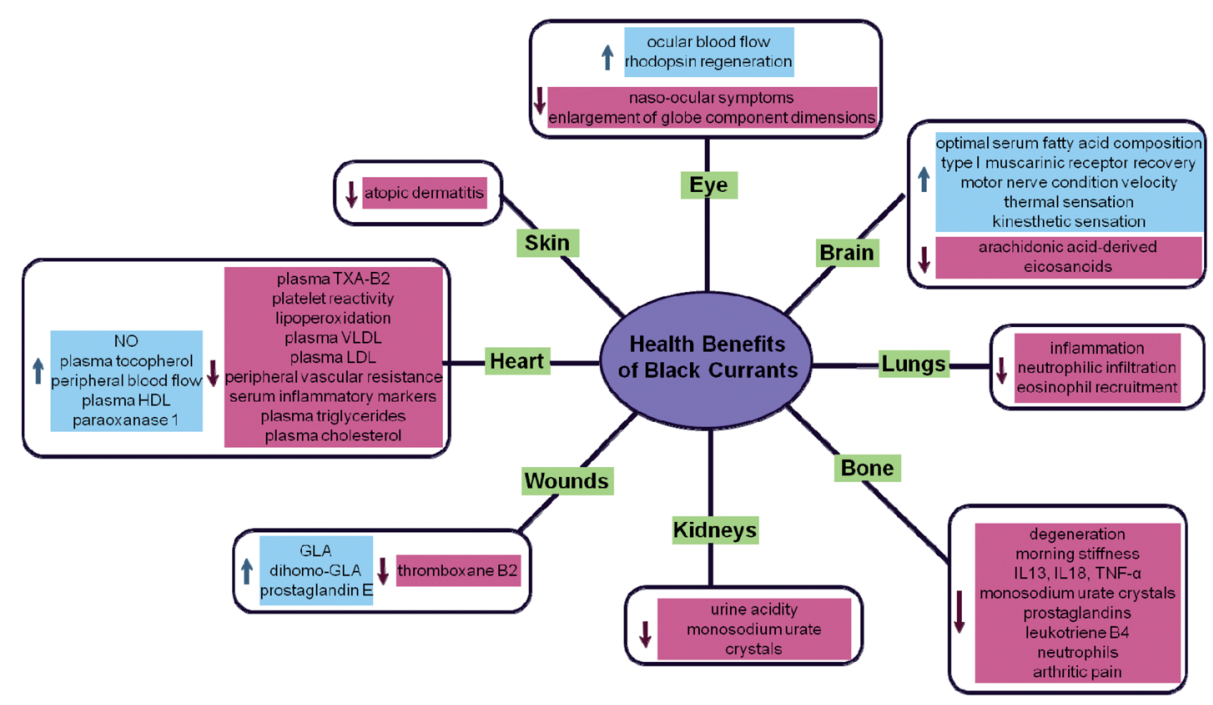

Fig. 4 An overview of therapeutic effects and related mechanisms of blackcurrants in various organs.

the effects of topical applications of $0.05 \mathrm{mg} \mathrm{kg}^{-1}$ body weight of GLA twice daily for a 3-4 week period on children with infantile seborrheic dermatitis. ${ }^{109}$

\section{Renal system}

Patients with gout experience painful inflammatory reactions to the formation of monosodium urate crystals. In addition to the painful joint depositions of these crystals, patients with gout also often experience urate stone formation in their kidneys, which is treated by alkalinizing the urine. Berry juice has been used to modulate urinary $\mathrm{pH}$ for the treatment of ailments such as kidney stones. ${ }^{110}$ Kebler and co-workers ${ }^{111}$ studied the effect of consumption of the juice of berries, such as blackcurrant juice, and their effect on kidney stone formation. In this study, blackcurrant juice alkalinized urine and also increased the excretion of both citric and oxalic acid.

\section{Wounds}

A major area of health-modifying applications of blackcurrant administration involves tapering inflammatory processes, which occur during stress-causing or injurious events. An example of such a situation would be in the setting of acquired burn wounds. An investigation regarding the effects of GLA supplementation into the parenteral nutrition of critically ill patients afflicted with burn injuries demonstrated that plasma levels of anti-inflammatory agents such as GLA, DGLA, and prostaglandin E increased, while levels of pro-thrombotic, pro-inflammatory agents, such as thromboxane $\mathrm{B} 2$, were reduced. ${ }^{112}$ This results in the suppression of inflammation at the burn site as well as the inhibition of thrombus formation.

\section{Safety and bioavailability of blackcurrants}

There has not been much extensive research specifically concerning the safety or toxicity of blackcurrants. Several studies exploring the various effects of the fruit have noted no major side effects from its ingestion. ${ }^{31}$ It has been noted that ingesting of $100 \mathrm{~g} \mathrm{day}^{-1}$ of blackcurrants, along with other berries containing a high quercetin concentration, over the course of at least 8 weeks demonstrates a $32-51 \%$ mean increase in serum quercetin levels, indicating the high bioavailability of quercetin. ${ }^{113}$ Urinary excretion of quercetin was demonstrated to be significantly increased in a short term, high intake diet of blackcurrant juice, while lipid oxidation in plasma appeared to decrease. ${ }^{61}$ It has been postulated that these effects may be related to several components of blackcurrant juice and cannot be solely attributed to its high concentration of quercetin. Another study using both animal and human models indicates that the maximum excretion of blackcurrant anthocyanins occurs $120 \mathrm{~min}$ following administration and slowly declines over the next $3 \mathrm{~h}$, but that the excreted amount is less than $0.1 \%$ of the ingested, also indicating a high bioavailability of anthocyanins. ${ }^{114}$ This finding is supported by human and rat models which exhibited maximum plasma concentrations after oral administration of the four blackcurrant anthocyanins. ${ }^{115}$ These studies merely describe the pharmacodynamics of administered chemical constituents of blackcurrants, however, and do not elucidate any detrimental effects. Considerable efforts have been taken to understand the effects of herbal supplements, such as blackcurrant extracts, especially with regard to drug interactions, yet there still exists a critical need to perform well-designed systematic toxicity evaluations of both pre-clinical and clinical studies for blackcurrant phytoconstituents. ${ }^{116}$

\section{Conclusion and future directions}

Based on emerging evidence obtained from pre-clinical and clinical studies, as highlighted in this review, blackcurrants have demonstrated significant therapeutic potential in a myriad of disease states (summarized in Fig. 4). This is due to the common pathways that many disease processes share and the manner by which the blackcurrant constituents can exert its effects upon similar processes. 
There are many directions by which this field of knowledge can increase and the applications it can have in health and disease states. Specific mechanisms of action, such as anthocyanidin effects on leukocyte transmigration, need to be further explored in terms of the specific pathways and molecules involved. Additionally, the specific gross and micro-anatomic free radical scavenging activity of blackcurrant constituents, including various aspects of the gastrointestinal tract or intracellular compartments, should be studied in depth.

The scope of the modulating effects of blackcurrants can be greatly and methodically expanded, given the broad spectrum of effects that blackcurrant phytochemicals demonstrate, including anti-inflammatory, antioxidant and antimicrobial properties. Several clinical trials were able to provide positive results that described beneficial outcomes of the treatment under examination, such as the efficacy of topical GLA on skin lesions caused by atopic dermatitis, but failed to provide control groups to validate and ensure the accuracy of the claimed result.

When obtaining results in clinical trials, the use of conventional, quantitative clinical measurements should be used as opposed to subjective data collection. For example, when ascertaining the effects of a certain level of GLA administration in the treatment of rheumatoid arthritis, definitive results should be presented in the form of erythrocyte sedimentation rates, rheumatoid factor levels or C-reactive protein levels.

Human trials studying the effect of blackcurrants on pathological processes can be conducted to collect data on its ability to modify and affect disease. For instance, though anthocyanin content has been shown to improve night vision, the clinical trials completed included only healthy subjects with normal and above-normal day-time vision. While familiarity of the anti-oxidative properties of blackcurrants have been established to increase normal physiological functioning and prevention of disease such as atherosclerosis, more clinical studies using subjects with substandard functioning (e.g. patients with below-normal vision) or disease processes should be studied to further ascertain the disease-treatment efficacy of blackcurrants.

Additionally, studies using isolated biochemical constituents, for example phenolic content in varying blackcurrant cultivars, can be explored to identify the effects of blackcurrants on specific disease states in human or animal models.

A few critical areas need to be systematically evaluated to ensure the therapeutic success of blackcurrants. The role of synergistic properties of dietary phytochemicals and the contribution to their therapeutic potential have become the subject of significant interest and intense investigation. It has been suggested that the health benefits offered by dietary agents are due to the complex mixture of phytonutrients present in the entire plant part such as fruit. ${ }^{117,118}$ It would be particularly beneficial to evaluate the synergistic potential of blackcurrants since the fruits consist of a myriad of bioactive phytoconstituents. It would also be highly beneficial to conduct a "headto-head" evaluation of individual blackcurrant phytoconstituents with the whole spectrum of phytochemicals present in the entire fruit. The development of novel dosage forms of blackcurrants is another area which needs attention to ensure an improved bioavailability.

\section{Abbreviations}

\begin{tabular}{ll}
\hline AA & Arachidonic acid \\
CAPAS & Cassis polysaccharide \\
CGN & Carrageenan \\
COX-2 & Cyclooxygenase \\
DENA & Diethylnitrosamine \\
DGLA & Dihomo-gamma-linolenic acid \\
EFA & Essential fatty acids \\
EPA & Eicosapentanoic acid \\
GLA & $\gamma$-Linolenic acid \\
GSH & Glutathione \\
HCC & Hepatocellular carcinoma \\
$\mathrm{H}_{2} \mathrm{O}_{2}$ & Hydrogen peroxide \\
IL & Interleukin \\
LDL & Low density lipoprotein \\
LPS & Lipopolysaccharide \\
NF- $\kappa$ B & Nuclear factor- $\kappa$ B \\
NO & Nitric oxide \\
Nrf2 & Nuclear factor E2-related factor 2 \\
PAC & Proanthocyanidin \\
PUFAs & Polyunsaturated fatty acids \\
TNF- $\alpha$ & Tumor necrosis factor- $\alpha$ \\
VLDL & Very low density lipoprotein \\
\end{tabular}

\section{Acknowledgements}

The research on blackcurrants, carried out at the authors' laboratories and described in this article, was partially supported by a New Faculty Startup Research Fund from the Northeast Ohio Medical University College of Pharmacy (Rootstown, OH) to A.B. and the Hungarian Scientific Research Fund (grant OTKA K72771) and the Hungarian National Development Agency (grant TÁMOP 4.2.2-08/1) to J.H. The authors express their sincere thanks to Laura Colwell and Lisa Barker, Ocasek Medical Library of the Northeast Ohio Medical University, for gathering articles for this review and Greg Quinn, Walnut Grove Farm (Staatsburg, NY), for providing the blackcurrant pictures.

\section{References}

1 G. D. Stoner, L. S. Wang, N. Zikri, T. Chen, S. S. Hecht, C. Huang, C. Sardo and J. F. Lechner, Cancer prevention with freeze-dried berries and berry components, Semin. Cancer Biol., 2007, 17, 403410.

2 N. P. Seeram, Berry fruits: compositional elements, biochemical activities and impact of their intake on human health, performance, and disease, J. Agric. Food Chem., 2008, 56, 627-629.

3 C. C. Neto, J. W. Amoroso and A. M. Liberty, Anticancer activities of cranberry phytochemicals: an update, Mol. Nutr. Food Chem, 2008, 52, S18-S27.

4 M. E. Schreckinger, J. Lotton, M. A. Lila and E. G. de Mejia, Berries from South America: a comprehensive review on chemistry, health potential, and commercialization, J. Med. Food, 2010, 13, 233-246.

5 N. P. Seeram, Emerging research supporting the positive effects of berries on human health and disease prevention, J. Agric. Food Chem., 2012, in press.

6 S. Zafra-Stone, T. Yasmin, M. Bagchi, A. Chatterjee, J. A. Vinson and D. Bagchi, Berry anthocyanins as novel antioxidants in human health and disease prevention, Mol. Nutr. Food Res., 2007, 51, 675-683. 
7 M. Battino, J. Beekwilder, B. Denoyes-Rothan, M. Laimer, G. J. McDougall and B. Mezzetti, Bioactive compounds in berries relevant to human health, Nutr. Rev., 2009, 67, S145-S150.

8 N. P. Seeram, Recent trends and advances in berry health benefits research, J. Agric. Food Chem., 2010, 58, 3869-3870.

9 G. D. Stoner, L. S. Wang and C. Casto, Laboratory and clinical studies of cancer chemoprevention by antioxidants in berries, Carcinogenesis, 2008, 29, 1665-1674.

10 G. D. Stoner, Foodstuffs for preventing cancer: the preclinical and clinical development of berries, Cancer Prev. Res., 2009, 2, 187194.

11 M. S. Baliga and J. J. Dsouza, Amla (Emblica officinalis Gaertn), a wonder berry in the treatment and prevention of cancer, Eur. J. Cancer Prev., 2011, 20, 225-239.

12 E. M. Brown, C. I. Gill, G. J. McDougall and D. Stewart, Mechanisms underlying the anti-proliferative effects of berry components in in vitro models of colon cancer, Curr. Pharm. Biotechnol., 2012, 13, 200-209.

13 R. M. Brennan, Currant and gooseberries (Ribes L) in The encyclopedia of Fruit and Nut Crops, Ed. J. Janick, CABI. Inc, New York, 2005, pp. 191-295.

14 C. Declume, Anti-inflammatory evaluation of a hydroalcoholic extract of blackcurrant leaves (Ribes nigrum), J. Ethnopharmacol., 1989, 27, 91-98.

15 T. Suzutani, M. Ogasawara, I. Yoshida, M. Azuma and Y. M. Knox, Anti-herpes virus activity of an extract of Ribes nigrum L ., Phytother. Res., 2003, 17, 609-613.

16 J. Tabart, C. Kevers, J. Pincemail, J. O. Defraigne and J. Dommes, Antioxidant capacity of blackcurrant varies with organ, season, and cultivar, J. Agric. Food Chem., 2006, 54, 6271-6276.

17 J. G. Bordonaba and L. A. Terry, Biochemical profiling and chemometric analysis of seventeen UK-grown blackcurrant cultivars, J. Agric. Food Chem., 2008, 56, 7422-7430.

18 G. Jaworska, M. Sady, T. Grega, E. Bernas and K. Pogon, Qualitative comparison of blackcurrant and blackcurrant-whey beverages, Food Sci. Technol. Int., 2011, 17, 331-341.

19 J. Tabart, C. Kevers, D. Evers and J. Dommes, Ascorbic acid, phenolic acid, flavonoid, and carotenoid profiles of selected extracts from Ribes nigrum, J. Agric. Food Chem., 2011, 59, 47634770.

20 T. P. Mikkonen, K. R. Maatta, A. T. Hukkanen, H. I. Kokko, A. R. Torronen, S. O. Karenlampi and R. O. Karjalainen, Flavonol contentvaries among blackcurrant cultivars, J. Agric. Food Chem., 2001, 49, 3274-3277.

21 K. Kampuss and S. Strautina, Evaluation of blackcurrant genetic resources for sustainable production, J. Fruit Ornam. Plant Res., 2004, 12, 147-158.

22 P. Raudsepp, H. Kaldmäe, A. Kikas, A. V. Libek and T. Püssa, Nutritional quality of berries and bioactive compounds in the leaves of blackcurrant (Ribes nigrum L.) cultivars evaluated in Estonia, J. Berry Res., 2010, 1, 53-59.

23 V. Nour, I. Trandafir and M. R. Ionica, Ascorbic acid, anthocyanins, organic acids and mineral content of some black and red currant cultivars, Fruits, 2011, 66, 353-362.

24 R. A. Moyer, K. E. Hummer, C. E. Finn, B. Frei and R. E. Wrolstad, Anthocyanins, phenolics, and antioxidant capacity in diverse small fruits: vaccinium, rubus, and ribes, J. Agric. Food Chem., 2002, 50, 519-525.

25 I. L. Nielsen, G. R. Haren, E. L. Magnuseen, L. O. Dragstead and S. E. Rasmussen, Quantification of anthocyanins in commercial blackcurrant juices by simple high-performance liquid chromatography. Investigation of their $\mathrm{pH}$ stability and antioxidative potency, J. Agric. Food Chem., 2003, 51, 58615866.

26 K. Maatta, A. Kamal-Eldin and R. Torronen, High-performance liquid chromatography (HPLC) analysis of Phenolic compounds in berries with diode array and electrospray ionization mass spectrometric (MS) detection: Ribes species, J. Agric. Food Chem., 2003, 51, 6736-6744.

27 A. Delazar, L. Khodaie, J. Afshar, L. Nahar and S. D. Sarker, Isolation and free-radical-scavenging properties of cyanidin 3-Oglycosides from the fruits of Ribes biebersteinii Berl, Acta Pharm., 2010, 60, 1-11.

28 R. Slimestad and H. Solheim, Anthocyanins from blackcurrants (Ribes nigrum L.), J. Agric. Food Chem., 2002, 50, 3228-3231.
29 K. Maatta, A. Kamal-Eldin and R. Torronen, Phenolic compounds in berries of black, red, green and white currants (Ribes $s p$.), Antioxid. Redox Signaling, 2001, 3, 981-993.

$30 \mathrm{~S}$. Hakkinen and S. Auriola, High performance liquid chromatography with electrospray ionization mass spectrometry and diode array ultraviolet detection in the identification of flavonol aglycones and glycosides in berries, J. Chromatogr., A, 1998, 829, 91-100.

31 J. Watson, M. L. Byars, P. McGill and A. W. Kelman, Cytokine and prostaglandin production by monocytes of volunteers and rheumatoid arthritis patients treated with dietary supplements of blackcurrant seed oil, Rheumatology, 1993, 32, 1055-1058.

32 L. J. Leventhal, E. G. Boyce and R. B. Zurier, Treatment of rheumatoid arthritis with blackcurrant seed oil, Rheumatology, 1994, 33, 847-852.

33 L. Y. Song, W. X. Lu, J. Hu, Y. Zhang, W. B. Yin, Y. H. Chen, S. T. Hao, B. L. Wang, R. R. Wang and Z. M. Hu, Identification and functional analysis of the genes encoding $\Delta^{6}$-desaturase from Ribes nigrum, J. Exp. Bot., 2010, 61, 1827-1838.

34 D. Wu, M. Meydani, L. S. Leka, Z. Nightingale, G. J. Handelman, J. B. Blumberg and S. N. Meydani, Effect of dietary supplementation with blackcurrant seed oil on the immune response of healthy elderly subjects, Am. J. Clin. Nutr., 1999, 70, $536-543$.

35 C. Lengsfeld, A. Deters, G. Faller and A. Hensel, High molecular weight polysaccharides from blackcurrant seeds inhibit adhesion of Helicobacter pylori to human gastric mucosa, Planta Med., 2004, 70, 620-626.

36 J. Zippel, A. Deters, D. Pappai and A. Hensel, A high molecular arabinogalactan from Ribes nigrum $L$ : influence on cell physiology of human skin fibroblasts and keratinocytes and internalization into cells via endosomal transport, Carbohydr. Res., 2009, 344, 1001-1008.

37 P. G. Walker, R. Viola, M. Woodhead, L. Jorgensen, S. Gordon, R. Brennan and R. Hancock, Ascorbic acid content of blackcurrant fruit is influenced by both genetic and environmental factors, Func. Plant. Sci. Biotech., 2010, 1, 40-52.

38 J. Salobir, T. P. Zontar, A. Levart and V. Rezar, The comparison of blackcurrant juice and vitamin $\mathrm{E}$ for the prevention of oxidative stress, Int. J. Vitam. Nutr. Res., 2010, 80, 5-11.

39 S. Hakkinen, M. Heinonen, S. Karenlampi, H. Mykkanen, J. Ruuskanen and R. Torronen, Screening of selected flavonoids and phenolic acids in 19 berries, Food Res. Int., 1999, 32, 345353.

40 N. P. Seeram, W. J. Aronson, Y. Zhang, S. M. Henning, A. Morro, R. P. Lee, M. Sartippour, D. M. Harris, M. Rettig, M. A. Suchard, A. J. Pantuck, A. Belldegrun and D. Heber, Pomegranate ellagitannin-derived metabolites inhibit prostate cancer growth and localize to the mouse prostate gland, J. Agric. Food Chem., 2007, 19, 7732-7737.

41 I. Lefevre, J. Ziebel, C. Guignard, A. Sorokin, O. Tikhonova, N. Dolganova, L. Hoffmann, P. Eyzaguirre and J. F. Hausman, Evaluation and comparison of nutritional quality and bioactive compounds of berry fruits from Lonicera caerulea, Ribes $L$. species and Ribes ideaus grown in Russia, J. Berry Res., 2011, 3, 159167.

42 V. Kockmann, D. Spielmann, H. Traitler and M. Lagrarde, Inhibitory effect of stearidonic acid (18:4 n-3) on platelet aggregation and arachidonic oxygenation, Lipids, 1989, 12, 1004 1007.

43 D. Spielmann, U. Bracco, H. Traitler, G. Crozier, R. Holman, M. Ward and R. Cotter, Alternative lipids to usual omega 6 PUFAS: gamma-linolenic acid, alpha-linolenic acid, stearidonic acid, EPA, etc., J. Parenter. Enteral Nutr., 1988, 12, 111S-123S.

44 D. E. Barre, Potential of evening primrose, borage, blackcurrant and fungal oils in human health, Ann. Nutr. Metab., 2001, 45, 47-57.

45 K. A. Lyall, S. M. Hurst, J. Cooney, D. Jensen, K. Lo, R. D. Hurst and L. M. Stevenson, Short-term blackcurrant extract consumption modulates exercise-induced oxidative stress and lipopolysaccharidestimulated inflammatory responses, Am. J. Physiol.: Regul. Integr. Comp. Physiol., 2009, 297, R70-R81.

46 T. R. Balstad, I. Paur, M. Poulsen, J. Markowski, K. Kolodziejczyk, L. O. Dragsted, M. C. W. Myhrstad and R. Blomhoff, Apple, cherry, and blackcurrant increases nuclear factor kappa B activation in liver of transgenic mice, Nutr. Cancer, 2010, 62, 841-848. 
47 A. Borthakur, S. Bhattacharyya, P. K. Dudeja and J. K. Tobacman, Carrageenan induces interleukin-8 production through distinct BCL10 pathway in normal human colonic epithelial cells, Am. J. Physiol.: Gastrointest. Liver Physiol., 2006, 292, G829-G838.

48 N. Garbacki, M. Tits, L. Angenot and J. Damas, Inhibitory effects of proanthocyanidins from Ribes nigrum leaves on carrageenin acute inflammatory reactions induced in rats, BMC Pharmacol., 2004, 4, 25.

49 N. Garbacki, M. Tits and J. Damas, Anti-inflammatory effect of natural proanthocyanidins: pharmacological evaluation on in vivo models, Eur. J. Physiol, 2003, 446, R5.

50 D. Bagchi, C. K. Sen, S. D. Ray, D. K. Das, M. Bagchi, H. G. Preuss and J. A. Vinson, Molecular mechanisms of cardioprotection by novel grapeseed proanthocyanidin extract, Mutat. Res., Fundam. Mol. Mech. Mutagen., 2003, 523-524, 87-97.

51 D. Helbig, A. Wagner, M. Glei, S. Basu, R. Schubert and G. Jahneis, Blackcurrant seed press residue increases tocopherol concentrations in serum and stool whilst biomarkers in stool and urine indicate increased oxidative stress in human subjects, Br. J. Nutr., 2009, 102, 554-562.

52 G. M. Rubanyi, E. H. Ho, E. H. Cantor, W. C. Lumma and L. H. Botelho, Cytoprotective function of nitric oxide: inactivation of superoxide radicals produced by human leukocytes, Biochem. Biophys. Res. Commun., 1991, 181, 1392-1397.

53 Y. Yoshiki, T. Kahara, K. Okubo, T. Sakabe and T. Yamasaki, Superoxide- and 1,1-diphenyl-2-picrylhydrazyl radical-scavenging activities of soyasaponin beta $\mathrm{G}$ related to gallic acid, Biosci., Biotechnol., Biochem., 2001, 65, 2162-2165.

54 R. J. Gryglewski, S. Moncada and R. M. Palmer, Bioassay of prostacyclin and endothelium-derived relaxing factor (EDRF) from procine aortic endothelial cells, Br. J. Pharmacol., 1986, 87, 685-694.

55 K. Viljanen, P. Kylli, R. Kivikari and M. Heinonen, Inhibition of protein and lipid oxidation in liposomes by berry phenolics, $J$. Agric. Food Chem., 2004, 52, 7419-7424.

56 I. Nielsen, L. Dragsted, G. Ravn-Haren, R. Freese and S. E. Rasmussen, Absorption and excretion of blackcurrant anthocyanins in humans and Watanabe heritable hyperlipidemic rabbits, J. Agric. Food Chem., 2005, 51, 2813-2820.

57 S. Ehala, M. Vaher and M. Kaljurand, Characterization of phenolic profiles on Northern European berries by capillary electrophoresis and determination of their antioxidant activity, J. Agric. Food Chem., 2005, 53, 6484-6490.

58 G. Borges, A. Degeneve, W. Mullen and A. Crozier, Identification of flavonoid and phenolic antioxidants in blackcurrants, blueberries, raspberries, red currants, and cranberries, J. Agric. Food Chem., 2010, 58, 3901-3909.

59 L. Estevez, N. Otero and R. A. Mosquera, A computational study on the acidity dependence of radical-scavenging mechanisms of anthocyanidins, J. Phys. Chem. B, 2010, 29, 9706-9712.

60 H. Matsumoto, Y. Nakamura, M. Hirayama, Y. Yoshiki and K. Okubo, Antioxidant activity of blackcurrant anthocyanin aglycons and their glycosides measured by chemiluminescence in a neutral $\mathrm{pH}$ region and in human plasma, J. Agric. Food Chem., 2002, 50, 5034-5037.

61 J. F. Young, S. E. Nielsen, J. Haraldsdottir, B. Daneshvar, S. T. Lauridsen, P. Knuthsen, A. Crozier, B. Sandstrom and L. O. Dragsted, Effect of fruit juice intake on urinary quercetin excretion and biomarkers of antioxidative status, Am. J. Clin. Nutr., 1999, 69, 87-94.

62 M. Rosenblat, N. Volkova, J. Attias, R. Mahamid and M. Aviram, Consumption of polyphenolic-rich beverages (mostly pomegranate and blackcurrant juices) by healthy subjects for a short term increased serum antioxidant status, and the serum's ability to attenuate macrophage cholesterol accumulation, Food Funct., 2010, 1, 99-109.

63 R. Puupponen-Pimia, L. Nohynek, C. Meier, M. Kahkonen, M. Heinonen, A. Hopia and K. M. Caldentey, Antimicrobial properties of phenolic compounds from berries, J. Appl. Microbiol., 2001, 90, 494-507.

64 A. Cisowska, D. Wojnicz and A. B. Hendrich, Anthocyanins as antimicrobial agents of natural plant origin, Nat. Prod. Commun., 2011, 6, 149-156.

65 L. J. Nohynek, H. L. Alakomi, M. P. Kahkonen, M. Heinonen, I. M. Helander, K. M. Oksman-Caldentey and R. H. Puupponen-
Pimia, Berry phenolics: antimicrobial properties and mechanisms of action against severe human pathogens, Nutr. Cancer, 2006, 54, $18-32$.

66 J. Santos, V. D. La, C. Bergeron and D. Grenier, Inhibition of hostand bacteria-derived proteinases by natural anthocyanins, $J$. Periodont. Res., 2011, 46, 550-557.

67 Y. M. Knox, T. Suzutani, I. Yosida and M. Azuma, Anti-influenza virus activity of crude extract of Ribes nigrum, L, Phytother. Res., 2003, 17, 120-122.

68 Y. M. Knox, K. Hayashi, T. Suzutani, M. Ogaswara, I. Yoshida, R. Shiina, A. Tsukui, N. Terahara and M. Azuma, Activity of anthocyanins from fruit extract of Ribes nigrum $L$. against influenza A and B viruses, Acta Virologica, 2001, 45, 209-215.

69 I. Edirisinghe, K. Banaszewski, J. Cappozzo, D. McCarthy and B. M. Burton-Freeman, Effect of blackcurrant anthocyanins on the activation of endothelial nitric oxide synthase (eNOS) in vitro in human endothelial cells, J. Agric. Food Chem., 2011, 59, 86168624.

70 J. A. Joseph, D. R. Fisher and A. N. Carey, Fruit extracts antagonize $\mathrm{A} \beta$ or DA-induced deficits in $\mathrm{Ca}^{2+}$ flux in M1-transfected COS-7 cells, J. Alzheimers Dis., 2004, 6, 403-411.

71 S. M. Hurst, T. K. McGhie, J. M. Cooney, D. J. Jensen, E. M. Gould, K. A. Lyall and R. D. Hurst, Blackcurrant proanthocyanidins augment IFN-gamma-induced suppression of IL-4 stimulated CCL26 secretion in alveolar epithelial cells, Mol. Nutr. Food Res., 2010, 54, S159-S170.

72 M. Olsson, K. E. Gustavsson, S. Andersson, А Nilsson and R. D. Duan, Inhibition of cancer cell proliferation in vitro by fruit and berry extracts and correlations with antioxidant levels, $J$. Agric. Food Chem., 2004, 52, 7264-7271.

73 Q. K. Wu, J. M. Koponen, H. M. Mykkänen and A. R. Törrönen, Berry phenolic extracts modulate the expression of $\mathrm{p} 21^{\mathrm{WAF} 1}$ and Bax but not Bcl-2 in HT-29 colon cancer cells, J. Agric. Food Chem., 2007, 55, 1156-1163.

74 G. J. McDougall, H. A. Ross, M. Ikeji and D. Stewart, Berry extracts exert different antiproliferative effects against cervical and colon cancer cells grown in vitro, J. Agric. Food Chem., 2008, 56, 3016-3023.

75 D. Boivin, M. Blanchette, S. Barrette, A. Moghrabi and R. Béliveau, Inhibition of cancer cell proliferation and suppression of TNFinduced activation of NF-KB by edible berry juice, Anticancer Res., 2007, 27, 937-948.

76 R. Takata, R. Yamamoto, T. Yanai, T. Konno and T. Okubo, Immunostimulatory effects of a polysaccharide-rich substance with antitumor activity isolated from blackcurrant (Ribes nigrum L.), Biosci., Biotechnol., Biochem., 2005, 69, 2042-2050.

77 L. Holtung, S. Grimmer and K. Aaby, Effect of processing of blackcurrant press-residue on polyphenol composition and cell proliferation, J. Agric. Food Chem., 2011, 59, 3632-3640.

78 A. Bishayee, E. Háznagy-Radnai, T. Mbimba, P. Sipos, P. Morazzoni, A. S. Darvesh, D. Bhatia and J. Hohmann, Anthocyanin-rich black currant extract suppresses the growth of human hepatocellular carcinoma cells, Nat. Prod. Commun., 2010, 5, 1613-1618.

79 M. M. Engler, Comparative study of diets enriched with evening primrose, blackcurrant, borage or fungal oils on blood pressure and pressor responses in spontaneously hypertensive rats, Prostaglandins, Leukotrienes Essent. Fatty Acids, 1993, 49, 809-814.

80 P. Pregnolato, M. Maranesi, I. Bosi, M. Cocchi, S. Coccheri, M. Frascaro and V. Barzanti, Effect of diets containing different amounts of precursor and derivative fatty acids on serum TXB2, Prostaglandins, Leukotrienes Essent. Fatty Acids, 1996, 55, 32-328.

81 J. Frank, A. Kamal-Eldin, T. Lundh, K. Maatta, R. Torrnen and B. Vessby, Effects of dietary anthocyanins on tocopherols and lipids in rats, J. Agric. Food Chem., 2002, 50, 7226-230.

82 Y. Nakamura, H. Matsumoto and K. Todoki, Endotheliumdependent vasorelaxation induced by blackcurrant concentrate in rat thoracic aorta, Jpn. J. Pharmacol., 2002, 89, 29-35.

83 R. Vecera, N. Skottova, P. Vana, L. Kazdova, Z. Chmela, Z. Svagera, D. Waltera, J. Ulrichova and V. Simanek, Antioxidant status, lipoprotein profile and liver lipids in rats fed on highcholesterol diet containing currant oil rich in n-3 and n-6 polyunsaturated fatty acids, Physiol. Res., 2003, 52, 177-187.

84 V. M. Breinholt, S. E. Nielsen, P. Knuthsen, S. T. Lauridsen, B. Daneshvar and A. Sorensen, Effects of commonly consumed 
fruit juices and carbohydrates on redox status and anticancer biomarkers in female rats, Nutr. Cancer, 2003, 45, 46-52.

85 H. Matsumoto, K. E. Kamm, J. T. Stull and H. Azuma, Delphinidin-3-rutinoside relaxes the bovine ciliary smooth muscle through activation of ETB receptor and NO/cGMP pathway, Exp. Eye Res., 2005, 80, 313-322.

86 K. Iwasaki-Kurashige, R. Y. Loyage-Rendon, H. Matsumoto, T. Tokunaga and H. Azuma, Possible mediators involved in decreasing peripheral vascular resisitance with blackcurrant concentrate (BC) in hind-limb perfusion model of the rat, Vasc. Pharmacol., 2006, 44, 215-233.

87 K. C. Dines, M. A. Cotter and N. E. Cameron, Effectiveness of natural oils as sources of gamma-linoleic acid to correct peripheral nerve conduction velocity abnormalities in diabetic rats: modulation by thromboxane A2 inhibition, Prostaglandins, Leukotrienes Essent. Fatty Acids, 1996, 55, 159-165.

$88 \mathrm{H}$. Matsumoto, Y. Nakamura, H. Iida, K. Ito and H. Ohguro, Comparative assessment of distribution of blackcurrant anthocyanins in rabbit and rat ocular tissues, Exp. Eye Res., 2006, 83, 348-356.

89 H. Iida, Y. Nakamura, H. Matsumoto, Y. Takeuchi, S. Harano, M. Ishihara and O. Katsumi, Effect of black-currant extract on negative lens-induced ocular growth in chicks, Ophthalmic Res., $2010,44,242-250$

90 G. Tate and R. B. Zurier, Suppression of monosodium urate crystalinduced inflammation by blackcurrant seed oil, Agents Actions, 1994, 43, 35-38.

91 R. A. Karmali, L. Adams and J. R. Trout, Plant and marine n-3 fatty acids inhibit experimental metastasis of rat mammary adenocarcinoma cells, Prostaglandins, Leukotrienes Essent. Fatty Acids, 1993, 48, 309-314.

92 R. Takata, T. Yanai, R. Yamamoto and T. Konno, Improvement of the antitumor activity of blackcurrant polysaccharide by an enzyme treatment, Biosci., Biotechnol., Biochem., 2007, 71, 1342-1344.

93 A. Bishayee, T. Mbimba, R. Thoppil, E. Háznagy-Radnai, P. Sipos, A. S. Darvesh, H. Folkesson and J. Hohmann, Anthocyanin-rich black currant (Ribes nigrum L.) extract affords chemoprevention against diethylnitrosamine-induced hepatocellular carcinogenesis in rats, J. Nutr. Biochem., 2011, 22, 1035-1046.

94 A. Bishayee, R. J Thoppil, A. Mandal, A. S. Darvesh, V. Ohanyan, J. G. Meszaros, E. Háznagy-Radnai, J. Hohmann and D. Bhatia, Black currant phytoconstituents exert chemoprevention of diethylnitrosamine-initiated hepatocarcinogenesis by suppression of the inflammatory response, Mol. Carcinog., 2012, in press.

95 R. J. Thoppil, D. Bhatia, K. F. Barnes, E. Háznagy-Radnai, J. Hohmann, A. S. Darvesh and A. Bishayee, Black currant anthocyanins abrogate oxidative stress through Nrf2-mediated antioxidant mechanisms in a rat model of hepatocellular carcinoma, Curr. Cancer Drug Targets, 2012, in press.

96 D. A. Stone, M. W. Hawke, M. LaMonte, S. J. Kittner, J. Acosta, M. Corretti, C. Sample, T. R. Price and G. D. Plotnick, Ulcerated atherosclerotic plaques in the thoracic aorta are associated with cryptogenic stroke: a multiplane transesophageal echocardiographic study, Am. Heart J., 1995, 130, 105-108.

97 H. Matsumoto, E. Takenami, K. Iwasaki-Kurashige, T. Osada, T. Katsumura and T. Hamaoka, Effects of blackcurrant anthocyanin intake on peripheral muscle circulation during typing work in humans, Eur. J. Appl. Physiol., 2005, 94, 36-45.

98 R. L. Tahvonen, U. S. Schwab, K. M. Linderborg, H. M. Mykkanen and H. P. Kallio, Blackcurrant seed soil and fish oil supplements differ in their effects on fatty acid profiles on plasma lipids, and concentrations of serum total and lipoprotein lipids, plasma glucose and insulin, J. Nutr. Biochem., 2005, 16, 353-359.

99 C. Dalgard, F. Nielsen, J. D. Morrow, H. Enghusen-Poulsen, T. Jonung, M. Horder and M. P. de Maat, Supplementation with orange and blackcurrant juice, but not vitamin E, improves inflammatory markers in patients with peripheral arterial disease, Br. J. Nutr., 2009, 101, 263-269.

100 Z. Fa-lin, W. Zhen-yu, H. Yan, Z. Tao and L. Kang, Efficacy of blackcurrant oil soft capsule, a Chinese herbal drug, in hyperlipidemia treatment, Phytother. Res., 2010, 24, S209-S213.
101 Y. Jin, D. Alimbetov, T. George, M. H. Gordon and J. A. Lovegrove, A randomised trial to investigate the effects of acute consumption of a blackcurrant juice drink on markers of vascular reactivity and bioavailability of anthocyanins in human subjects, Eur. J. Clin. Nutr., 2011, 65, 849-856.

102 Y. Zhu, M. Xia, Y. Yang, F. Liu, Z. Li, Y. Hao, M. Mi, T. Jin and W. Ling, Purified anthocyanin supplementation improves endothelial function via NO-cGMP activation in hypercholesterolemic individuals, Clin. Chem., 2011, 57, 1524-1533.

103 M. Diboune, G. Ferard, Y. Ingenbleek, P. A. Tulasne, B. Calon, M. Hasselmann, P. Sauder, S. Spielmann and P. Metais, Composition of phospholipid fatty acids in red blood cell membranes of patients in intensive care units: effects of different intakes of soybean oil, medium-chain triglycerides, and blackcurrant seed oil, J. Parenter. Enteral Nutr., 1992, 16, 136141.

104 H. Nakaishi, H. Matsumoto, S. Tominaga and M. Hirayama, Effects of blackcurrant anthocyaoside intake of dark adaptation and VDT work induced transient refractive alteration in healthy humans, J. Altern. Complementary Med., 2000, 6, 553-562.

105 H. Matsumoto, Y. Nakamura, S. Tachibanaki, S. Kawamura and M. Hirayama, Stimulatory effect of cyaniding-3-glycosides on the regeneration of rhodopsin, J. Agric. Food Chem., 2003, 51, 35603563.

106 K. Dejima, A. Ohshima, T. Yanai, R. Yamamoto, R. Takata and T. Yoshikawa, Effects of polysaccharide derived from blackcurrant on relieving clinical symptoms of Japanese cedar pollinosis: a randomized double-blind, placebo-controlled trial, Biosci., Biotechnol., Biochem., 2007, 71, 3019-3025.

107 N. Garbacki, L. Angenot, C. Bassleer, J. Damas and M. Tits, Effects of prodelphinidins isolated from Ribes nigrum on chondrocyte metabolism and Cox activity, Naunyn-Schmiedebergs Arch. Pharmacol., 2002, 365, 434-441.

108 M. Cameron, J. J. Gagnier and S. Chrubasik, Herbal therapy for treating rheumatoid arthritis, Cochrane Database Syst. Rev, 2011, 1, CD002948.

109 A. Fiocchi, M. Sala, P. Signorini, G. Banderall, C. Agontoni and E. Riva, The efficacy and safety of $\gamma$-linolenic acid in the treatment of infantile atopic dermatitis, J. Int. Med. Res., 1994, 22, 24-32.

110 H. D. Kahn, V. A. Panariello, J. Saeli, J. R. Sampson and E. Schwartz, Effect of cranberry juice on urine, J. Am. Diet Assoc., 1967, 51, 251-254

111 T. Kebler, B. Jansen and A. Hesse, Effect of blackcurrant-, cranberry- and plum juice consumption on risk factors associated with kidney stone formation, Eur. J. Clin. Nutr., 2002, 56, 10201023.

112 P. C. Calder, Hot topics in parenteral nutrition. Rationale for using new lipid emulsions in parenteral nutrition and a review of the trials performed in adults, Proc. Nutr. Soc., 2009, 68, 252-260.

113 I. Erlund, J. Marniemi, P. Hakala, E. G. Alfthan, E. Meririnne and A. Aro, Consumption of blackcurrants, lingonberries and bilberries increases serum quercetin concentrations, Eur. J. Clin. Nutr., 2003, 57, 37-42.

114 T. K. McGhie, G. D. Ainge, L. E. Barnett, J. M. Cooney and D. J. Jensen, Anthocyanin glycosides from berry fruit are absorbed and excreted unmetabolized by both humans and rats, $J$. Agric. Food Chem., 2003, 51, 4539-4548.

115 H. Matsumoto, H. Inaba, M. Kishi, S. Tominaga, M. Hirayama and T. Tsuda, Orally administered delphinidin 3-rutinoside and cyanidin 3-rutinoside are directly absorbed in rats and humans and appear in the blood as the intact forms, J. Agric. Food Chem., 2001, 49, 15461551.

116 U. Werneke, J. Earl, C. Seydel, O. Horn, P. Crichton and D. Fannon, Potential health risk of complementary alternative medicines in cancer patients, Br. J. Cancer, 2004, 90, 408-413.

117 R. H. Liu, Potential synergy of phytochemicals in cancer prevention: mechanism of action, J. Nutr., 2004, 134, 3479S-3485S.

118 T. M. de Kok, S. G. van Breda and M. M. Manson, Mechanisms of combined action of different chemopreventive dietary compounds, Eur. J. Nutr., 2008, 47, 51-59. 